\title{
The PICTURE study: diagnostic accuracy of multiparametric MRI in men requiring a repeat prostate biopsy
}

Lucy A M Simmons ${ }^{1,2,12}$, Abi Kanthabalan 1,2,12, Manit Arya ${ }^{2}$, Tim Briggs ${ }^{2,3}$, Dean Barratt ${ }^{4}$, Susan C Charman ${ }^{5,6}$, Alex Freeman ${ }^{7}$, James Gelister ${ }^{3}$, David Hawkes ${ }^{4}$, Yipeng Hu ${ }^{4}$, Charles Jameson ${ }^{7}$, Neil McCartan ${ }^{1,2}$, Caroline M Moore ${ }^{1,2}$, Shonit Punwani ${ }^{8,9}$, Navin Ramachandran ${ }^{8}$, Jan van der Meulen ${ }^{5,6}$, Mark Emberton ${ }^{1,2,13}$ and Hashim U Ahmed A $^{\star 1,2,10,11,13}$

${ }^{1}$ Division of Surgery and Interventional Science, University College London, Faculty of Medical Sciences, 21 University Street, London WC1E 7PN, UK; ${ }^{2}$ Department of Urology, UCLH NHS Foundation Trust, London, UK; ${ }^{3}$ Department of Urology, The Royal Free London NHS Foundation Trust, London, UK; ${ }^{4}$ Centre for Medical Imaging and Computing, Department of Computer Science, University College London, London, UK; ${ }^{5}$ Department of Health Services Research and Policy, London School of Hygiene and Tropical Medicine, London, UK; ${ }^{6}$ Clinical Effectiveness Unit, The Royal College of Surgeons of England, London, UK; ${ }^{7}$ Department of Pathology, UCLH NHS Foundation Trust London, UK; ${ }^{8}$ Department of Radiology, UCLH NHS Foundation Trust, London, UK; ${ }^{9}$ Centre for Medical Imaging, Division of Medicine, Faculty of Medical Sciences, University College London, London, UK; ${ }^{10}$ Division of Surgery, Department of Surgery and Cancer, Faculty of Medicine, Imperial College London, London, UK and ${ }^{11}$ Department of Urology, Imperial College Healthcare NHS Trust, London, UK

Background: Transrectal prostate biopsy has limited diagnostic accuracy. Prostate Imaging Compared to Transperineal Ultrasound-guided biopsy for significant prostate cancer Risk Evaluation (PICTURE) was a paired-cohort confirmatory study designed to assess diagnostic accuracy of multiparametric magnetic resonance imaging (mpMRI) in men requiring a repeat biopsy.

Methods: All underwent 3T mpMRI and transperineal template prostate mapping biopsies (TTPM biopsies). Multiparametric MRI was reported using Likert scores and radiologists were blinded to initial biopsies. Men were blinded to mpMRI results. Clinically significant prostate cancer was defined as Gleason $\geqslant 4+3$ and/or cancer core length $\geqslant 6 \mathrm{~mm}$.

Results: Two hundred and forty-nine had both tests with mean (s.d.) age was 62 (7) years, median (IQR) PSA 6.8 ng ml (4.98-9.50), median (IQR) number of previous biopsies 1 (1-2) and mean (s.d.) gland size $37 \mathrm{ml}$ (15.5). On TTPM biopsies, 103 (41\%) had clinically significant prostate cancer. Two hundred and fourteen (86\%) had a positive prostate mpMRI using Likert score $\geqslant 3$; sensitivity was $97.1 \%$ (95\% confidence interval (Cl): 92-99), specificity 21.9\% (15.5-29.5), negative predictive value (NPV) 91.4\% (76.9-98.1) and positive predictive value (PPV) 46.7\% (35.2-47.8). One hundred and twenty-nine (51.8\%) had a positive mpMRI using Likert score $\geqslant 4$; sensitivity was 80.6\% (71.6-87.7), specificity 68.5\% (60.3-75.9), NPV 83.3\% (75.4-89.5) and PPV 64.3\% (55.4-72.6).

Conclusions: In men advised to have a repeat prostate biopsy, prostate mpMRI could be used to safely avoid a repeat biopsy with high sensitivity for clinically significant cancers. However, such a strategy can miss some significant cancers and overdiagnose insignificant cancers depending on the mpMRI score threshold used to define which men should be biopsied.

*Correspondence: Professor HU Ahmed; E-mail: hashim.ahmed@ucl.ac.uk.

${ }^{12} \mathrm{~J}$ oint first authors have made an equal contribution to this study and manuscript.

${ }^{13}$ Joint senior authors have made an equal contribution to this study and manuscript.

Received 23 July 2016; revised 22 January 2017; accepted 6 February 2017; published online 28 March 2017

(C) 2017 Cancer Research UK. All rights reserved 0007-0920/17 
The prostate cancer diagnostic pathway is very different to that of almost all other solid organ cancers, in that it is calibrated to detect subclinical disease but often misses clinically important disease (Shaw et al, 2014). The imprecision comes from the transrectal ultrasound-guided biopsy (TRUS biopsy) - a semirandom deployment of needles into the prostate - that is the standard recommendation to a man with an elevated PSA. Men in whom diagnostic uncertainty remains unresolved often require repeat biopsy (Abrahams et al, 2015).

Multiparametric magnetic resonance imaging (mpMRI) incorporates a number of imaging sequences that assess anatomy and tissue characteristics such as cellular density and vascularity (Valerio et al, 2014; Siddiqui et al, 2015; Turkbey et al, 2016). It could be used as a triage diagnostic test by identifying those men who might avoid a repeat prostate biopsy (Bossuyt et al, 2006). The Prostate Imaging Compared to Transperineal Ultrasound-guided biopsy for significant prostate cancer Risk Evaluation (PICTURE) trial (Simmons et al, 2014) was designed to overcome methodological limitations related to the use of either TRUS biopsy or radical prostatectomy as reference standards, with the former being inaccurate and the latter incorporating selection biases as men had to both test positive for cancer on a TRUS biopsy and then choose to undergo surgery. It is likely that these inherently different populations (contingent on the method of histological verification) harbour different burdens of disease.

The PICTURE trial was a paired-cohort validating confirmatory study designed to provide level $1 \mathrm{~b}$ evidence on the diagnostic accuracy of mpMRI in men who required further biopsies (Phillips et al, 2009; Valerio et al, 2015). In other words, our study comprised men who had tested either negative on a first TRUS biopsy and had some indication for a repeat evaluation or tested positive and required some form of reclassification. Our reference standard was transperineal template prostate mapping biopsies (TTPM biopsies), which are both accurate and avoid many of the described biases. Transperineal template prostate mapping biopsies can be applied to almost all men under evaluation and overcome the random error of TRUS biopsy by sampling the whole prostate every $5 \mathrm{~mm}$ (Crawford et al, 2013).

\section{MATERIALS AND METHODS}

The PICTURE trial was a single-centre, ethics committeeapproved, registered validating confirmatory study reported to STARD (Bossuyt et al, 2003). The full details of our protocol have been published (Simmons et al, 2014). Ethics committee approval for the study was granted by London City Road and Hampstead National Research Ethics Committee (reference 11/LO/1657) and the trial was registered on 6 December 2011. The study opened to recruitment on 11 January 2012 and completed recruitment on 29 January 2014.

Eligibility. Men were eligible for the study if they had undergone prior TRUS biopsy and were advised to undergo further biopsies as part of standard care.

Index test. All eligible men underwent the index test (mpMRI) using a $3 \mathrm{~T}$ magnetic field strength scanner with a pelvic-phased array coil. Magnetic resonance imaging sequences included T1weighted, T2-weighted, diffusion weighting with high $b$-value $(b=2000)$ sequence and apparent diffusion coefficient map using multiple $b$-values $(b=0,150,500,1000)$ and dynamic contrast enhancement with gadolinium (Magnevist). Complete sequence details can be found in our protocol publication (Simmons et al, 2014). Multiparametric MRIs were reported by an expert urologic radiologist with over 5 years of experience in interpreting prostate MRIs. The radiologist was blinded to previous TRUS-biopsy results, but given the PSA level and any other risk factors.
Reporting was carried out using a 5-point Likert scale for the likelihood of the presence of clinically significant disease: ' 1 ' and ' 2 ' were designated for prostates 'highly unlikely' and 'unlikely' to harbour clinically significant prostate cancer, respectively, scores of ' 4 ' and ' 5 ' for glands 'likely' and 'highly likely' to harbour clinically significant disease, and a score of ' 3 ' for glands in which the likelihood of the presence of clinically significant cancer was equivocal. This scoring system was based on the outputs of a consensus group (Dickinson et al, 2011) that was convened before the publishing of the PIRADS mpMRI reporting consensus (Barentsz et al, 2012), although the two systems have subsequently been found to be similar (Rosenkrantz et al, 2013; Rastinehad et al, 2015). A random selection of 50 cases was re-reported by a second expert radiologist to allow assessment of interobserver variability.

Reference test. Patients were blinded to the mpMRI results to minimise non-compliance and selection bias. Men underwent the reference test (TTPM biopsies) performed according to a set protocol regardless of the imaging findings and without image registration regardless of the mpMRI scoring. In summary, mapping using $5 \mathrm{~mm}$ sampling was obtained using core needles inserted via a brachytherapy grid fixed on a stepper. In most prostates, two biopsies at each grid point were required to sample the full craniocaudal gland length. All biopsies were reported by one of two expert uropathologists of $>20$ years of experience each who were blinded to the mpMRI reports. All negative biopsies were double-reported for quality control. The cancer core length (CCL) was reported as the actual amount of cancer seen in each core without counting the intervening areas of benign glands.

Target condition. As it was inappropriate to use histological criteria for clinical significance developed for TRUS biopsy, disease significance was defined by criteria developed and validated for use with TTPM biopsies (Ahmed et al, 2011). Our primary outcome was based on the presence of dominant Gleason pattern 4 or greater (i.e., Gleason $\geqslant 4+3$ ) or a CCL involvement of $\geqslant 6 \mathrm{~mm}$ in any one location of any Gleason score. We used definition 2 for secondary outcome analyses (Gleason $\geqslant 3+4$ and/ or CCL $\geqslant 4 \mathrm{~mm}$ ) as well as the presence of any Gleason score 7 or more.

Sample size calculation. The sample size calculation was performed for the primary objective of calculating the negative predictive value (NPV) of mpMRI, using a precision-based estimate (Flahault et al, 2005). Targeting an NPV of $90 \%$ for definition one disease, for a binomial 95\% confidence interval (CI), with a confidence width $10 \%$, the number of patients needed with an absence of clinically significant prostate cancer on the reference test was 139 . Assuming a prevalence of $38 \%$ for UCL definition one disease in the population of interest based on data at our centre, which we have recently published but available at the time of designing PICTURE (Valerio et al, 2016), and assuming the performance characteristics of mpMRI equate to sensitivity and specificity of $\sim 70 \%$, an overall sample size of 316 patients was needed. As the prevalence of men without clinically significant disease on the reference test was not precisely known for the PICTURE study cohort, an interim analysis at 114 recruited men permitted an adjustment in recruitment to ensure that at least 139 men with a negative reference test were available for analysis.

Statistics. Sensitivity, specificity, PPV and NPV were calculated for all eligible men with binomial 95\% CIs. The index test was regarded as positive for an mpMRI score of 3 or greater for the purpose of the primary outcome and on a score of 4 or greater, as well as other definitions of clinical significance on the TTPM biopsies. Interobserver agreement was assessed using absolute and weighted kappa and proportion of agreement and assessed using area under receiver-operating characteristic (AUROC) curves. The weighted versions allow for the magnitude of the disagreements to 
be taken into account. The weighting system used resulted in the weights $0.75,0.5,0.25$ and 0 for MRI ratings scores that differed by $1,2,3$ and 4, respectively. STATA version 11.0 software was used for all analyses with any tests of significance using two-sided $P=0.05$ as the threshold for statistical significance.

\section{RESULTS}

Baseline characteristics. Three-hundred and thirty men were enrolled, and following 81 withdrawals, we had 249 completing both mpMRI and TTPM biopsies (Figure 1, STARD flowchart). Men eligible for analysis had mean (s.d.) age 62 years (7), median (IQR) PSA $6.8 \mathrm{ng} \mathrm{ml}^{-1}(4.8-9.8)$ and median (IQR) number of previous biopsies 1 (1-2) and gland size $37 \mathrm{ml}$ (26.8-50.0) (Table 1). One hundred and twenty-one (48.6\%) had Gleason 6 disease on TRUS biopsy, while $52(21.1 \%)$ had low volume Gleason 7 disease; 76 (30.5\%) had no prior cancer. At TTPM biopsies, a median (IQR) 49 (40-55) cores were taken. Two hundred and nine of 249 (84\%) in total had cancer on TTPM biopsy. The number of men free from clinically significant cancer on TTPM biopsies was 146 of $249(59 \%)$ and thus meeting our predefined sample size assumptions (Table 1).

Primary outcomes. When using mpMRI score of $\geqslant 3$ as a positive test result, $214(86 \%)$ had a positive prostate mpMRI. For definition one clinically significant prostate cancer, sensitivity was $97.1 \%$ (92-99), specificity $21.9 \%$ (15.5-29.5), NPV $91.4 \%$ (76.9-98.1) and PPV 46.7\% (35.2-47.8; Figure 2). Overall accuracy, as assessed by AUROC, was 0.74 (95\% CI 0.68-0.80).

Using mpMRI score $\geqslant 4$ as a positive test result, 129 (51.8\%) had a positive mpMRI. For definition of one disease, this conferred sensitivity of $80.6 \%(71.6-87.7)$, specificity of $68.5 \%(60.3-75.9)$, NPV of $83.3 \%(75.4-89.5)$ and PPV of $64.3 \%$ (55.4-72.6) (Figure 2). The negative likelihood ratio was $0.13(0.04-0.42)$ and $0.28(0.19-0.43)$ for an mpMRI score threshold of 3 and 4, respectively. Figure 2 illustrates histological outcomes on TTPM biopsies for each mpMRI score.

Secondary outcomes. We considered two scenarios using mpMRI to avoid a repeat biopsy. If an mpMRI score of $\geqslant 3$ defined a positive test, this would potentially allow 35 (14\%) to avoid a biopsy with 89 of 214 (41\%) clinically insignificant cancers (definition 1) detected (overdiagnosis) and 3 of 35 (9\%) clinically significant cancers missed (underdiagnosis). If a score of $\geqslant 4$ define a positive mpMRI, 120 (48\%) might avoid a biopsy with 40/129 (31\%) clinically insignificant cancers detected (overdiagnosis) and 20 of $120(17 \%)$ clinically significant cancers missed (underdiagnosis; Table 2). When considering definition 2 clinically significant cancers, the probability of underdiagnosing this type of significant cancer increases to $\sim 1$ in 3 (11 of 35) if men with an mpMRI reported as 1 or 2 wish to avoid a biopsy. Further, this would be 1 in 2 (54 of 120) if men with an mpMRI reported as 1, 2 or 3 wish to avoid biopsy (Table 3 ).

Agreement on the subset of mpMRIs that were double read was $58 \%(n=29$ of 50$)$ with $K=0.41$ (s.e. 0.08$)$, giving moderate agreement. Weighted agreement was $87.0 \%(K=0.52$, s.e. $=0.10)$ indicating good agreement. When comparing mpMRI scores for each reporter to histology on TTPM biopsies, there were minimal differences between each reporter in terms of AUROC analyses (reporter one AUROC $0.76(0.63-0.90)$ vs reporter two 0.75 (0.61-0.89)).

\section{Table 1. Patient demographics}

\begin{tabular}{|c|c|c|}
\hline & $\begin{array}{l}\text { Men enrolled, } \\
\qquad n=330\end{array}$ & $\begin{array}{c}\text { Men eligible for } \\
\text { analysis following } \\
\text { withdrawals, } n=249\end{array}$ \\
\hline \multicolumn{3}{|l|}{ Characteristic } \\
\hline $\begin{array}{l}\text { Age (years), mean (s.d.) } \\
\text { PSA at consent (ng ml }{ }^{-1} \text { ), } \\
\text { median (IQR) } \\
\text { Number of previous } \\
\text { biopsies, median (IQR) } \\
\text { MRI prostate volume }\left(\mathrm{cm}^{3}\right) \text {, } \\
\text { median (IQR) }\end{array}$ & $\begin{array}{c}63(7) \\
7.4(5.3-10.7) \\
1(1-2) \\
42.0(28.0-5.0)\end{array}$ & $\begin{array}{c}62(7) \\
6.8(4.8-9.8) \\
1(1-2) \\
37.0(26.8-50.0)\end{array}$ \\
\hline \multirow[t]{3}{*}{$\begin{array}{l}\text { Histological characteristics } \\
\text { median (IQR) }\end{array}$} & $\begin{array}{c}\text { Total number of } \\
\text { cores } \\
\text { Number of cancer } \\
\text { cores } \\
\text { MCCL (mm) }\end{array}$ & $\begin{array}{c}45(40-55) \\
6(2-11) \\
4(2-7)\end{array}$ \\
\hline & Gleason score & $N(\%)$ \\
\hline & $\begin{array}{c}\text { Benign } \\
3+3 \\
3+4 \\
4+3 \\
\geqslant 4+4 \\
3+5\end{array}$ & $\begin{array}{c}40(16.1) \\
66(26.5) \\
110(44.2) \\
29(11.7) \\
3(1.2) \\
1(0.4)\end{array}$ \\
\hline
\end{tabular}

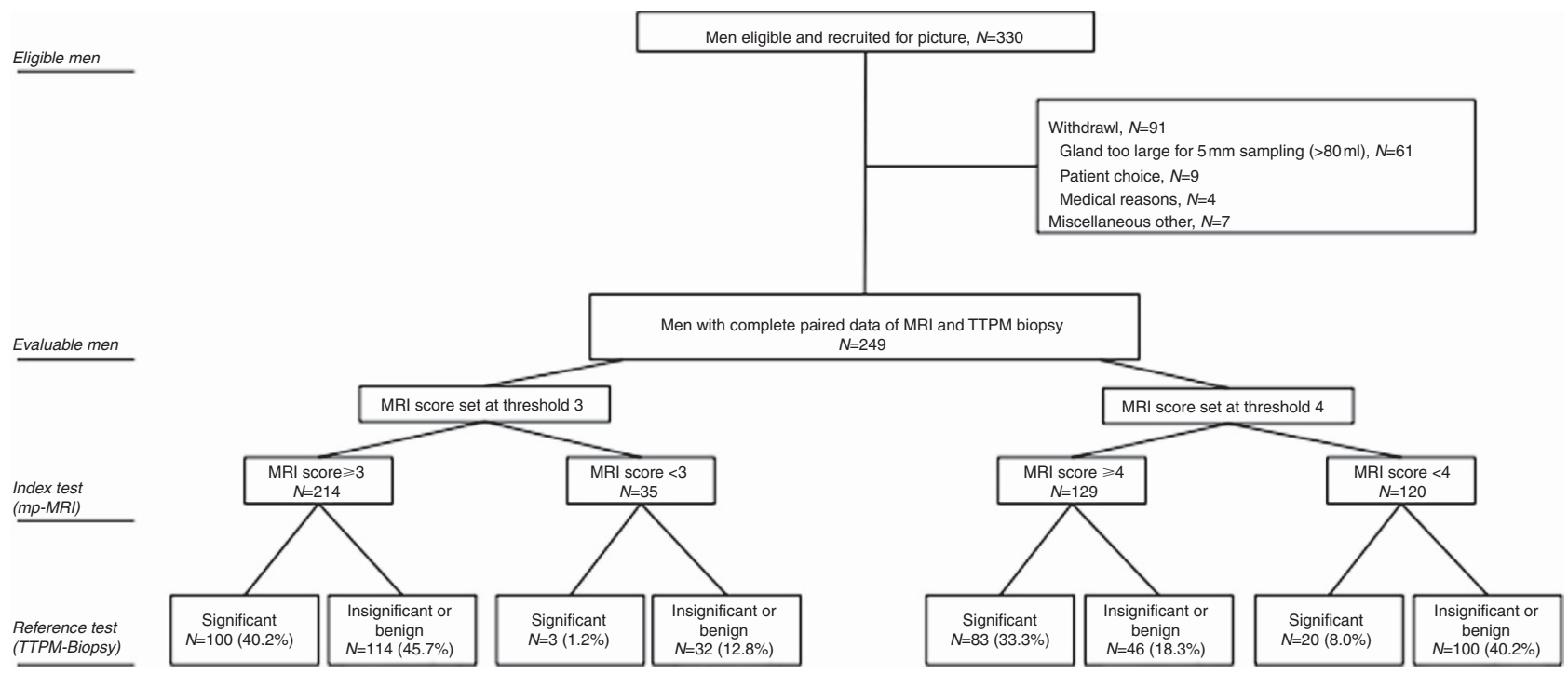

Figure 1. PICTURE trial flowchart compliant with STARD. 


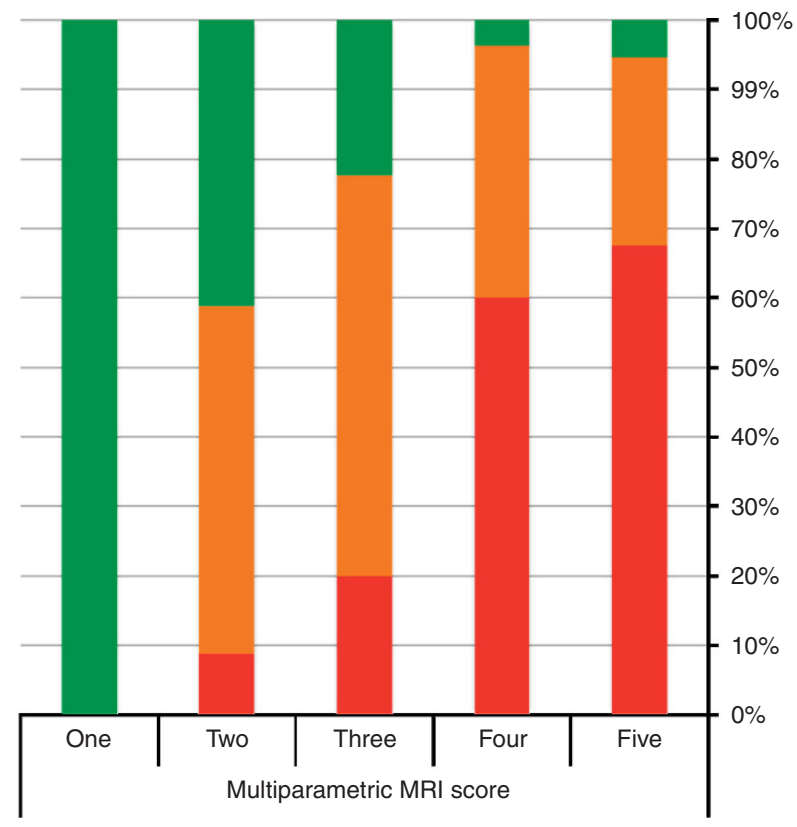

TTPM-biopsies

Benign

TTPM-biopsies

Clinically insignificant prostate cancer

TTPM-biopsies

Clinically significant prostate cancer

\begin{tabular}{|c|c|c|c|c|c|}
\hline & & \multicolumn{3}{|c|}{ TTPM-biopsies } & Total \\
\hline & & $\begin{array}{l}\text { Clinically } \\
\text { significant } \\
\text { prostate } \\
\text { cancer }\end{array}$ & $\begin{array}{l}\text { Clinically } \\
\text { insignificant } \\
\text { prostate } \\
\text { cancer }\end{array}$ & Benign & \\
\hline \multirow{5}{*}{$\begin{array}{l}\text { Multiparametric } \\
\text { MRI score }\end{array}$} & Five & 50 & 20 & 4 & 74 \\
\hline & Four & 33 & 20 & 2 & 55 \\
\hline & Three & 17 & 49 & 19 & 85 \\
\hline & Two & 3 & 17 & 14 & 34 \\
\hline & One & 0 & 0 & 1 & 1 \\
\hline Total & & 103 & 106 & 40 & 249 \\
\hline
\end{tabular}

Figure 2. Bar chart with associated contingency table demonstrating the histological outcome on TTPM biopsies for each MRI score when using the primary definition of clinical significant prostate cancer (Gleason $\geqslant 4+3$ and/or maximum CCL $\geqslant 6 \mathrm{~mm}$ ).

In detecting and ruling out definition of two clinically significant prostate cancer (Gleason $\geqslant 3+4$ and/or CCL $\geqslant 4 \mathrm{~mm}$ of any Gleason score), with an mpMRI score of $\geqslant 3$ as a positive test result, sensitivity was $93.5 \%$ (88.6-96.7), specificity $29.6 \%$ (20.0-40.8), NPV 68.6\% (50.7-83.1) and PPV 73.4\% (66.9-79.2; Figure 3). Overall accuracy was AUROC 0.76 (0.70-0.82). Table 3 presents scenarios for number biopsied and outcomes if mpMRI score 3 or 4 were used to designate a positive test.

There were no serious adverse events resulting from mpMRI. Serious adverse events resulting from TTPM biopsies occurred in 9 (3.6\%). Adverse events were assessed in 236 in a median of $38 \pm 56$ days after biopsy. Haematuria was reported in 220 (93.2\%), poor urine flow in $108(45.8 \%)$ and urinary retention in $56(23.7 \%)$. Urinary tract infection was diagnosed in $23(9.8 \%)$ and perineal skin infection in $8(3.4 \%)$. Rectal pain was reported in $59(25.1 \%)$, perineal pain in $95(40.3 \%)$ and perineal bruising in $136(57.6 \%)$. De novo erectile dysfunction occurred in $20.8 \%$, with two men requiring oral medication and the others recovering erectile function spontaneously after 3-6 weeks.

\section{DISCUSSION}

Our PICTURE trial results show that mpMRI in men who require repeat biopsies is able to accurately rule out clinically significant prostate cancer as shown by a high sensitivity and NPV. If men with an mpMRI reported as 1 or 2 wish to avoid a biopsy the probability of significant cancer is $\sim 1$ in 10 . In our study, this amounted to two cases with $6 \mathrm{~mm}$ of Gleason $3+3$ and a third case of $2 \mathrm{~mm}$ of Gleason $4+3$.

Our study has some limitations. First, the proportion scoring 1 or 2 was small (14\%) leading to low specificity. Second, our findings relate to an expert centre and whether these findings are reproducible in other non-expert centres requires further evaluation. Third, we were not able to report to the PIRADS system due to this protocol being set up before the PIRADS reporting schema. A future study will need to compare the two reporting systems. Last, our overall accuracy demonstrated by the AUROC value of 0.74 is somewhat $<0.80$ value that is widely accepted to be indicative of an optimal diagnostic test. This is due to the poor specificity of mpMRI and further reinforces that when suspicious, mpMRI cannot replace biopsy due to a high rate of false positives. It also alludes to the consequent detection of insignificant cancer, especially when a score threshold of 3 is used to designate a suspicious mpMRI.

Recent systematic reviews assessing the diagnostic accuracy of mpMRI found sensitivities ranging from 58 to $96 \%$, specificity 23 to $87 \%$ and NPV 63 to 98\% (de Rooij et al, 2014; Fütterer et al, 2015). The wide ranges reflected differences in mpMRI protocols, reference standards, study populations, disease prevalence and mpMRI reporting.

Our study relates to a heterogeneous patient population who had previous biopsy that was positive or negative. We mitigated any bias this might cause by our blinding strategy. Further, heterogeneity improves external validity, although we would advise caution in applying our results to the biopsy-naive population. The role of mpMRI in biopsy-naive men is subject to another study called PROMIS that has been reported recently (Ahmed et al, 2017). 
Table 2. Number of men avoiding biopsy and diagnosis rates for a target definition for significance on TTPM-biopsy of definition 1 (Gleason $\geqslant 4+3$ and/or maximum cancer core length $\geqslant 6 \mathrm{~mm}$ ) for each MRI score

\begin{tabular}{|c|c|c|}
\hline & \multicolumn{2}{|c|}{ mpMRI score threshold for positive } \\
\hline & mpMRI SCORE $\geqslant 3$ & mpMRI SCORE $\geqslant 4$ \\
\hline Avoid biopsy & $14 \%(35 / 249)$ & $48 \%(120 / 249)$ \\
\hline Biopsy & $86 \%(214 / 249)$ & $52 \%(129 / 249)$ \\
\hline $\begin{array}{l}\text { Overdiagnosed } \\
\text { insignificant cancer } \\
\text { (of those } \\
\text { undergoing a repeat } \\
\text { biopsy based on } \\
\text { mpMRI) }\end{array}$ & $41 \%(89 / 214)$ & $31 \%(40 / 129)$ \\
\hline $\begin{array}{l}\text { Diagnosed } \\
\text { Significant cancer } \\
\text { (of those } \\
\text { undergoing a repeat } \\
\text { biopsy based on } \\
\text { mpMRI) }\end{array}$ & $47 \%(100 / 214)$ & $64 \%(83 / 129)$ \\
\hline $\begin{array}{l}\text { Underdiagnosed } \\
\text { significant cancer } \\
\text { (of those not } \\
\text { undergoing a repeat } \\
\text { biopsy based on } \\
\text { mpMRI) }\end{array}$ & $9 \%(3 / 35)$ & $8 \%(20 / 120)$ \\
\hline $\begin{array}{l}\text { False positive on } \\
\text { mpMRI (of those } \\
\text { undergoing a repeat } \\
\text { biopsy based on } \\
\text { mpMRI) }\end{array}$ & $12 \%(25 / 214)$ & $5 \%(6 / 129)$ \\
\hline $\begin{array}{l}\text { Sensitivity (95\% } \\
\text { confidence interval) }\end{array}$ & $97.1 \%(91.7-99.4 \%)$ & $80.6 \%(71.6-87.7 \%)$ \\
\hline $\begin{array}{l}\text { Specificity (95\% } \\
\text { confidence interval) }\end{array}$ & $21.9 \%(15.5-29.5 \%)$ & $68.5 \%(60.3-75.9 \%)$ \\
\hline $\begin{array}{l}\text { NPV (95\% } \\
\text { confidence interval) }\end{array}$ & $91.4 \%(76.9-98.2 \%)$ & $83.3 \%(75.4-89.5 \%)$ \\
\hline $\begin{array}{l}\text { PPV (95\% } \\
\text { confidence interval) }\end{array}$ & $46.7 \%(39.9-53.7 \%)$ & $64.3 \%(55.4-72.6 \%)$ \\
\hline $\begin{array}{l}\text { AUROC (95\% } \\
\text { confidence interval) }\end{array}$ & $0.60(0.56-0.63)$ & $0.75(0.69-0.80)$ \\
\hline $\begin{array}{l}\text { Abbreviations: } A U R O C= \\
\text { metric magnetic resona } \\
\text { predictive value. }\end{array}$ & $\begin{array}{l}\text { inder receiver-operatin } \\
\text { naging; } N P V=\text { negati }\end{array}$ & $\begin{array}{l}\text { aracteristic; } m p M R I=\text { multipara } \\
\text { redictive value; } P P V=\text { positiv }\end{array}$ \\
\hline
\end{tabular}

A number of definitions of clinically significant prostate cancer are available that could have been used to define the target condition on the reference test (Lord et al, 2011; Valerio et al, 2016). We decided to use histological thresholds developed to stratify TTPM-biopsy outcomes. Other classification systems such as the commonly used Epstein criteria are based on using maximum CCL and the number of positive cores from TRUS biopsy and cannot be applied to TTPM biopsies.

The prevalence of clinically significant disease was high in PICTURE, which might be related to the fact that large glands ( $>80 \mathrm{ml}$ ) were unable to enter the study as TTPM biopsy would not be possibly due to bony public arch interference. However, such a high prevalence has been seen by others when applying TTPM biopsies to this group of men (Bittner et al, 2015); thus, it is possible that existing thresholds for clinical significance might need to be raised (Bratt et al, 2015; Valerio et al, 2016).

Currently, men who require a repeat prostate biopsy face either a further TRUS biopsy or TTPM biopsies. Some are using urinary or serum biomarkers to decide who should proceed to a repeat prostate biopsy. Transrectal ultrasound-guided biopsy can
Table 3. Number of men avoiding biopsy diagnosis rates for significance on TTPM-biopsy of definition 2 (Gleason $\geqslant 3+4$ and/or maximum cancer core length $\geqslant 4 \mathrm{~mm}$ ) for each MRI score

\begin{tabular}{|c|c|c|}
\hline & \multicolumn{2}{|c|}{ mpMRI score threshold for positive } \\
\hline & mpMRI score $\geqslant 3$ & mpMRI score $\geqslant 4$ \\
\hline Avoid biopsy & $14 \%(35 / 249)$ & $48 \%(120 / 249)$ \\
\hline Biopsy & $85 \%(214 / 249)$ & $52 \%(129 / 249)$ \\
\hline $\begin{array}{l}\text { Overdiagnosed } \\
\text { insignificant cancer } \\
\text { (of those } \\
\text { undergoing a } \\
\text { repeat biopsy } \\
\text { based on mpMRI) }\end{array}$ & $15 \%(32 / 214)$ & $7 \%(9 / 129)$ \\
\hline $\begin{array}{l}\text { Diagnosed } \\
\text { significant cancer } \\
\text { (of those } \\
\text { undergoing a } \\
\text { repeat biopsy } \\
\text { based on mpMRI) }\end{array}$ & $73 \%(157 / 214)$ & $88 \%(114 / 129)$ \\
\hline $\begin{array}{l}\text { Underdiagnosed } \\
\text { significant cancer } \\
\text { (of those not } \\
\text { undergoing a } \\
\text { repeat biopsy } \\
\text { based on mpMRI) }\end{array}$ & $31 \%(11 / 35)$ & $45 \%(54 / 120)$ \\
\hline $\begin{array}{l}\text { False positive on } \\
\text { mpMRI }\end{array}$ & $26 \%(57 / 214)$ & $12 \%(15 / 129)$ \\
\hline $\begin{array}{l}\text { Sensitivity ( } 95 \% \\
\text { confidence interval) }\end{array}$ & $93.5 \%$ (88.6-96.7\%) & $67.9 \%(60.2-74.8 \%)$ \\
\hline $\begin{array}{l}\text { Specificity ( } 95 \% \\
\text { confidence interval) }\end{array}$ & $29.6 \%$ (20.0-40.8\%) & $81.5 \%$ (71.3-89.2\%) \\
\hline $\begin{array}{l}\text { NPV ( } 95 \% \\
\text { confidence interval) }\end{array}$ & $68.6 \%(50.7-83.1 \%)$ & $55.0 \%(45.7-64.1 \%)$ \\
\hline $\begin{array}{l}\text { PPV (95\% } \\
\text { confidence interval) }\end{array}$ & $73.4 \%$ (66.9-79.2\%) & $88.4 \%$ (81.5-93.3\%) \\
\hline $\begin{array}{l}\text { AUROC (95\% } \\
\text { confidence interval) }\end{array}$ & $0.62(0.56-0.67)$ & $0.75(0.69-0.80)$ \\
\hline
\end{tabular}

continue to missclassify with men sometimes requiring a third or fourth biopsy (Abraham et al, 2015). In addition, TRUS biopsies carry risk of infection (1-4\%) and rising levels of life-threatening sepsis $(0.1 \%)$ as they traverse contaminated rectal mucosa with most men experiencing discomfort and bleeding (Loeb et al, 2013).

On the other hand, TTPM biopsies are highly accurate (Crawford et al, 2005) and accurately attribute prostate cancer risk (Valerio et al, 2016). A recent study (Crawford et al, 2013) comparing TTPM biopsies with whole-mount radical prostatectomy specimens it detected in all but one significant prostate cancer lesion - our protocol used the same $5 \mathrm{~mm}$ sampling frame in this study. However, TTPM biopsies require general anaesthesia with a side-effect profile that is higher than that of TRUS biopsy. The degree of morbidity, as assessed robustly in PICTURE, is high. The other disadvantage of TTPM biopsies is the risk of overdetection of clinically insignificant cancers (Valerio et al, 2016).

Serum and urinary biomarkers also hold promise and offer the potential of a noninvasive simple test that might allow men to make a decision whether to avoid a repeat biopsy (Leapman et al, 2016). However, two biomarkers (prostate health index and PCA3) were recently deemed less accurate and less cost-effective when compared with an imaging-based pathway by the UK National Institute of 


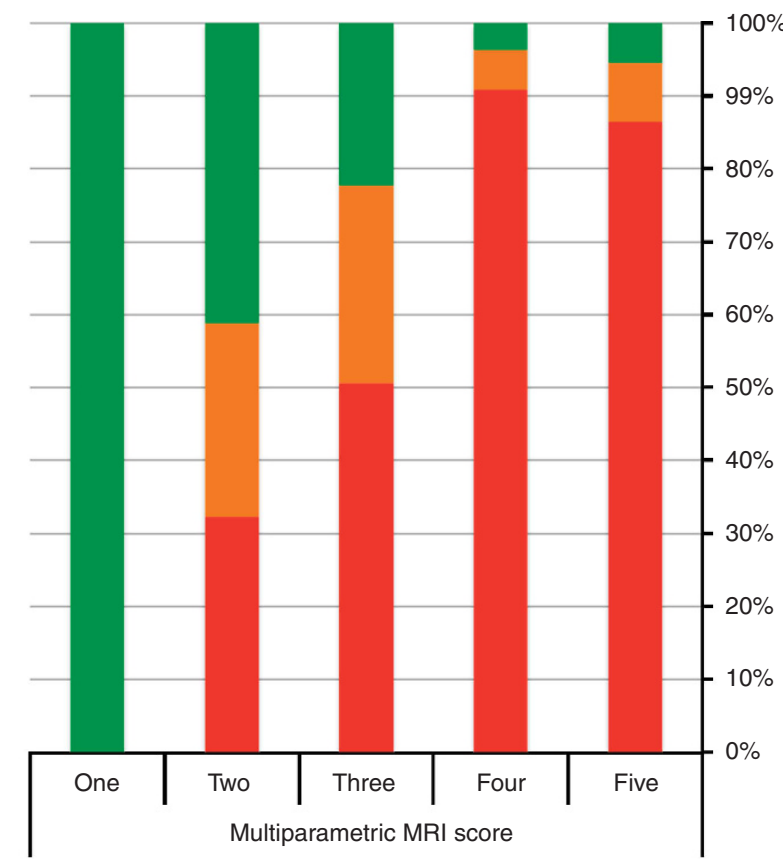

TTPM-biopsies

Benign

- TTPM-biopsies

Clinically insignificant prostate

cancer

TTPM-biopsies

Clinically significant prostate

cancer

\begin{tabular}{|c|c|c|c|c|c|}
\hline & & \multicolumn{3}{|c|}{ TTPM-biopsies } & \multirow[t]{2}{*}{ Total } \\
\hline & & $\begin{array}{l}\text { Clinically } \\
\text { significant } \\
\text { prostate } \\
\text { cancer }\end{array}$ & $\begin{array}{l}\text { Clinically } \\
\text { insignificant } \\
\text { prostate } \\
\text { cancer }\end{array}$ & Benign & \\
\hline \multirow{5}{*}{$\begin{array}{l}\text { Multiparametric } \\
\text { MRI SCORE }\end{array}$} & Five & 64 & 6 & 4 & 74 \\
\hline & Four & 50 & 3 & 2 & 55 \\
\hline & Three & 43 & 23 & 19 & 85 \\
\hline & Two & 11 & 9 & 14 & 34 \\
\hline & One & 0 & 0 & 1 & 1 \\
\hline TOTAL & & 168 & 41 & 40 & 249 \\
\hline
\end{tabular}

Figure 3. Bar chart with associated contingency table demonstrating the histological outcome on TTPM biopsies for each MRI score when using the secondary definition of clinically significant prostate cancer (Gleason $\geqslant 3+4$ and/or maximum $C C L \geqslant 4 \mathrm{~mm}$ ).

Clinical and Health Excellence (NICE Diagnostics Guideline, 2015). We acknowledge other fluidic biomarker panels such as the 4-kallikrein panel have demonstrated good performance characteristics and are undergoing further evaluation.

It is against these options that the role of mpMRI is considered. A man who is currently advised to undergo a repeat biopsy is faced with the alternatives of an inaccurate test, which confers a risk of sepsis (TRUS biopsy) compared with a highly accurate test that requires a general anaesthetic and confers other forms of morbidity but lower risk of sepsis (TTPM biopsies). He and his physician, upon looking at the performance characteristic of mpMRI in an expert centre, may wish to use this before a decision about repeating the biopsy.

Whether the use of mpMRI before biopsy might be costeffective requires further research (Willis et al, 2014; Cerantola et al, 2016). With an estimated one million prostate biopsies occurring every year in the United States and $~ 300000$ men undergoing repeat biopsies, the upfront costs of an mpMRI triage test need to be offset against the potential benefit of $\sim 30000$ fewer biopsies and fewer cases of clinically insignificant cancer, which often get treated unnecessarily. Nonetheless, one should not underestimate the issues of cost, skills and expertise in reporting mpMRI and carrying out targeted biopsies (Nassiri et al, 2015). men with a non-suspicious mpMRI who avoid an immediate biopsy should be told of the false-negative rate associated with such a strategy and undergo clinical follow-up. In addition, the high prevalence of suspicious mpMRI scans, when a score of 3 is used to indicate a positive mpMRI leading to biopsy, can also lead to overdiagnosis of insignificant cancers. Further research is required to determine whether targeted biopsies in conjunction with systematic biopsies or alone can achieve the high sensitivity seen in our PICTURE study.

\section{ACKNOWLEDGEMENTS}

We would thank the men who participated in this study. ME's research is supported by core funding from the United Kingdom's National Institute of Health Research (NIHR) UCLH/UCL Biomedical Research Centre. He was awarded NIHR Senior Investigator in 2015. HUA receives funding from the Medical Research Council (UK). PICTURE received funding from the US National Institute of Health (primary award 1R01CA135089; subaward via Riverside Research Institute NYO.G00351P.011741.12) and an unrestricted research grant from Advanced Medical Diagnostics SA.

\section{CONFLICT OF INTEREST}

HUA receives funding from Sonacare Medical, Sophiris and Trod Medical for other trials. Travel allowance was previously provided from Sonacare Inc. ME has stock interest in Nuada Medical Ltd. 
$\mathrm{He}$ is also a consultant to Steba Biotech and GSK. He receives travel funding from Sanofi Aventis, Astellas, GSK and Sonacare. He previously received trial funding or resources from GSK, Steba Biotech and Angiodynamics and currently receives funding for trials from Sonacare Inc., Sophiris Inc. and Trod Medical. AF has stock interest in Nuada Medical Ltd. DH is a founder shareholder in IXICO plc. DB and YH have a patent in image fusion, called SmartTarget. CMM receives funding from ProfBiotics and GSK. All the others authors declare no conflict of interest.

\section{REFERENCES}

Abraham NE, Mendhiratta N, Taneja SS (2015) Patterns of repeat prostate biopsy in contemporary clinical practice. J Urol 193(4): 1178-1184.

Ahmed HU, Hu Y, Carter T, Arumainayagam N, Lecornet E, Freeman A, Hawkes D, Barratt DC, Emberton M (2011) Characterizing clinically significant prostate cancer using template prostate mapping biopsy. J Urol 186(2): 458-464.

Ahmed HU*, Bosaily A*, Brown LC*, Gabe R, Kaplan R, Parmar MK, Collaco-Moraes Y, Ward K, Hindley RG, Freeman A, Kirkham AP, Oldroyd R, Parker C, Emberton M, the PROMIS study group (2017) Diagnostic accuracy of multi-parametric MRI and TRUS biopsy in prostate cancer (PROMIS): a paired validating confirmatory study. Lancet 389(10071): 815-822.

Barentsz JO, Richenberg J, Clements R, Choyke P, Verma S, Villeirs G, Rouviere O, Logager V, Fütterer JJ, European Society of Urogenital Radiology (2012) ESUR prostate MR guidelines 2012. Eur Radiol 22: 746-757.

Bittner N, Merrick GS, Bennett A, Butler WM, Andreini HJ, Taubenslag W, Adamovich E (2015) Diagnostic performance of initial transperineal template-guided mapping biopsy of the prostate gland. Am J Clin Oncol 38(3): 300-303.

Bossuyt PM, Reitsma JB, Bruns DE, Gatsonis CA, Glasziou PP, Irwig LM, Lijmer JG, Moher D, Rennie D, de Vet HC, Standards for Reporting of Diagnostic Accuracy (2003) Towards complete and accurate reporting of studies of diagnostic accuracy: The STARD Initiative. Ann Intern Med 138: $40-44$.

Bossuyt PM, Irwig L, Craig J, Glasziou P (2006) Comparative accuracy: assessing new tests against existing diagnostic pathways (published erratum appears in: BMJ 2006; 332(7554):1368). BMJ 332(7549): 1089-1092.

Bratt O, Folkvaljon Y, Loeb S, Klotz L, Egevad L, Stattin P (2015) Upper limit of cancer extent on biopsy defining very low-risk prostate cancer. BJU Int 116(2): 213-219.

Cerantola Y, Dragomir A, Tanguay S, Bladou F, Aprikian A, Kassouf W (2016) Cost-effectiveness of multiparametric magnetic resonance imaging and targeted biopsy in diagnosing prostate cancer. Urol Oncol 34(3): 119.e1-9.

Crawford ED, Wilson SS, Torkko KC, Hirano D, Stewart JS, Brammell C, Wilson RS, Kawata N, Sullivan H, Lucia MS, Werahera PN (2005) Clinical staging of prostate cancer: a computer-simulated study of transperineal prostate biopsy. BJU Int 96(7): 999-1004.

Crawford ED, Rove KO, Barqawi AB, Maroni PD, Werahera PN, Baer CA, Koul HK, Rove CA, Lucia MS, La Rosa FG (2013) Clinical-pathologic correlation between transperineal mapping biopsies of the prostate and three-dimensional reconstruction of prostatectomy specimens. Prostate 73(7): 778-787.

de Rooij M, Hamoen EH, Futterer JJ, Barentsz JO, Rovers MM (2014) Accuracy of multiparametric MRI for prostate cancer detection: a metaanalysis. AJR Am J Roentgenol 202: 343-351.

Dickinson L, Ahmed HU, Allen C, Barentsz JO, Carey B, Futterer JJ, Heijmink SW, Hoskin PJ, Kirkham A, Padhani AR, Persad R, Puech P, Punwani S, Sohaib AS, Tombal B, Villers A, van der Meulen J, Emberton M (2011) Magnetic resonance imaging for the detection, localisation, and characterisation of prostate cancer: recommendations from a European consensus meeting. Eur Urol 59(4): 477-494.

Flahault A, Cadilhac M, Thomas G (2005) Sample size calculation should be performed for design accuracy in diagnostic test studies. J Clin Epidemiol 58(8): 859-862.

Fütterer JJ, Briganti A, De Visschere P, Emberton M, Giannarini G, Kirkham A, Taneja SS, Thoeny H, Villeirs G, Villers A (2015) Can clinically significant prostate cancer be detected with multiparametric magnetic resonance imaging? A systematic review of the literature. Eur Urol 68(6): 1045-1053.

Leapman MS, Nguyen HG, Cooperberg MR (2016) Clinical utility of biomarkers in localized prostate cancer. Curr Oncol Rep 18(5): 30.

Loeb S, Vellekoop A, Ahmed HU, Catto J, Emberton M, Nam R, Rosario DJ, Scattoni V, Lotan Y (2013) Systematic review of complications of prostate biopsy. Eur Urol 64(6): 876-892.

Lord SJ, Staub LP, Bossuyt PM, Irwig LM (2011) Target practice: choosing target conditions for test accuracy studies that are relevant to clinical practice. BMJ 343: d4684.

Nassiri N, Natarajan S, Margolis DJ, Marks LS (2015) Targeted prostate biopsy: lessons learned midst the evolution of a disruptive technology. Urology 86(3): 432-438.

NICE Diagnostics Guideline (2015) Diagnosing Prostate Cancer: PROGENSA PCA3 assay and Prostate Health Index Diagnostics Guidance. Available at: https://www.nice.org.uk/guidance/dg17 (last accessed 3 June 2015).

Phillips B, Ball C, Sackett D, Badenoch D, Straus S, Haynes B, Dawes M (2009) Updated by J Howick, March 2009. Available at: http://www.cebm.net/ oxford-centre-evidence-based-medicine-levels-evidence-march-2009/.

Rastinehad AR, Waingankar N, Turkbey B, Yaskiv O, Sonstegard AM, Fakhoury M, Olsson CA, Siegel DN, Choyke PL, Ben-Levi E, Villani R (2015) Comparison of multiparametric MRI Scoring systems and the impact on cancer detection in patients undergoing MR US fusion guided prostate biopsies. PLoS One 10(11): e0143404.

Rosenkrantz AB, Lim RP, Haghighi M, Somberg MB, Babb JS, Taneja SS (2013) Comparison of interreader reproducibility of the prostate imaging reporting and data system and likert scales for evaluation of multiparametric prostate MRI. AJR Am J Roentgenol 201(4): W612-W618.

Shaw GL, Thomas BC, Dawson SN, Srivastava G, Vowler SL, Gnanapragasam VJ, Shah NC, Warren AY, Neal DE (2014) Identification of pathologically insignificant prostate cancer is not accurate in unscreened men. $\mathrm{Br} J$ Cancer 110(10): 2405-2411.

Siddiqui MM, Rais-Bahrami S, Turkbey B, George AK, Rothwax J, Shakir N, Okoro C, Raskolnikov D, Parnes HL, Linehan WM, Merino MJ, Simon RM, Choyke PL, Wood BJ, Pinto PA (2015) Comparison of MR/ultrasound fusion-guided biopsy with ultrasound-guided biopsy for the diagnosis of prostate cancer. JAMA 313(4): 390-397.

Simmons LA, Ahmed HU, Moore CM, Punwani S, Freeman A, Hu Y, Barratt D, Charman SC, Van der Meulen J, Emberton M (2014) The PICTURE study - prostate imaging (multi-parametric MRI and Prostate HistoScanning) compared to transperineal ultrasound guided biopsy for significant prostate cancer risk evaluation. Contemp Clin Trials 37(1): 69-83.

Turkbey B, Brown AM, Sankineni S, Wood BJ, Pinto PA, Choyke PL (2016) Multiparametric prostate magnetic resonance imaging in the evaluation of prostate cancer. CA Cancer J Clin 66(4): 326-336.

Valerio M, Donaldson I, Emberton M, Ehdaie B, Hadaschik BA, Marks LS, Mozer P, Rastinehad AR, Ahmed HU (2014) Detection of clinically significant prostate cancer using magnetic resonance imagingultrasound fusion targeted biopsy: a systematic review. Eur Urol 68(1): $8-19$.

Valerio M, Willis S, van der Meulen J, Emberton M, Ahmed HU (2015) Methodological considerations in assessing the utility of imaging in early prostate cancer. Curr Opin Urol 25(6): 536-542.

Valerio M, Anele C, Bott SR, Charman SC, van der Meulen J, El-Mahallawi H, Emara AM, Freeman A, Jameson C, Hindley RG, Montgomery BS, Singh PB, Ahmed HU, Emberton M (2016) The prevalence of clinically significant prostate cancer according to commonly used histological thresholds in men undergoing template prostate mapping biopsies. J Urol 195(5): 1403-1408.

Willis SR, Ahmed HU, Moore CM, Donaldson I, Emberton M, Miners AH, van der Meulen J (2014) Multiparametric MRI followed by targeted prostate biopsy for men with suspected prostate cancer: a clinical decision analysis. BMJ Open 4(6): e004895.

This work is published under the standard license to publish agreement. After 12 months the work will become freely available and the license terms will switch to a Creative Commons AttributionNonCommercial-Share Alike 4.0 Unported License. 